\title{
THE ASSOCIATION OF DEMENTIA WITH RADIOLOGICALLY DEMONSTRATED CEREBRAL ATROPHY
}

\author{
BY \\ R. H. GOSLING \\ From the National Hospital for Nervous Diseases, Queen Square, London
}

Dementia beginning in late middle life raises many medical problems. It is caused by a variety of pathological processes which even after postmortem examination of the brain may remain obscure (McMenemey, 1941 ; Rothschild, 1941). If some cerebral lesion, such as atrophy or tumour, can be detected during life the diagnosis can be put on a firmer footing, and it is to this end that cases presenting with dementia are often investigated by means of a lumbar air encephalogram (A.E.G.). If a tumour is revealed by an A.E.G. the problem is considered settled. If cerebral atrophy is demonstrated then this is assumed to account for the dementia (Chodoff, Simon, and Freeman, 1948). But we are not always so successful. Sometimes no lesion is revealed by an A.E.G. and the dementia remains unexplained. On the other hand, gross generalized cerebral atrophy is occasionally found in a patient without the slightest impairment of mental function, but in whom an A.E.G. was thought necessary for some other reason.

The purpose of this paper is to determine the value of the A.E.G. in investigating the dementias of late middle life, and for this the experience of routine examination in a neurological hospital has been surveyed. Exact pathological diagnosis, though desirable, was not available in this material, and so the problem has been restricted to cases of dementia after the age of 45 for which no definite cause, such as tumour, could be found.

\section{Investigation}

Abstracts were made of the case notes of all patients coming to the National Hospital for Nervous Diseases, Queen Square, London, between April, 1949, and March, 1953, who showed dementia beginning after the age of 45 and who had had an A.E.G. done. Cases of the following conditions were excluded: Huntington's chorea, other degenerative conditions with systemic involvement of the central nervous system, cerebral tumour, head injury, and arteriosclerotic dementia that was beyond dispute, i.e., dementia dating from a cerebrovascular accident. We were thus left with a collection of certain conditions characterized by the onset of dementia after the age of 45 . Presumably it included senile, Alzheimer's, Pick's, and some arteriosclerotic dementias, together with a few conditions that were misdiagnosed or in which the diagnosis was left in doubt. There were 68 such cases (Table I). Because of the indefinite composition of the case material throughout this paper the data are presented in five-year age groups.

TABLE I

INCIDENCE OF CEREBRAL ATROPHY IN CASES OF DEMENTIA

\begin{tabular}{|c|c|c|c|c|c|}
\hline \multirow{2}{*}{ Age } & \multirow{2}{*}{$\begin{array}{l}\text { No. of } \\
\text { Cases of } \\
\text { Dementia } \\
\text { Examined } \\
\text { by A.E.G. }\end{array}$} & \multicolumn{2}{|c|}{$\begin{array}{l}\text { Dementia with } \\
\text { Atrophy }\end{array}$} & \multicolumn{2}{|c|}{$\begin{array}{c}\text { Dementia without } \\
\text { Atrophy }\end{array}$} \\
\hline & & No. & $\%$ & No. & $\%$ \\
\hline $\begin{array}{l}45- \\
50- \\
55- \\
60- \\
65\end{array}$ & $\begin{array}{r}7 \\
18 \\
22 \\
16 \\
5\end{array}$ & $\begin{array}{r}6 \\
16 \\
19 \\
12 \\
5\end{array}$ & $\begin{array}{r}86 \\
89 \\
86 \\
75 \\
100\end{array}$ & $\begin{array}{l}1 \\
2 \\
3 \\
4 \\
0\end{array}$ & $\begin{array}{r}14 \\
11 \\
14 \\
25 \\
0\end{array}$ \\
\hline Total & 68 & 58 & 85 & 10 & 15 \\
\hline
\end{tabular}

* The dementia was judged clinically. From a perusal ofthê records it was rated as slight, moderate, or marked, but it should be remembered that these records iwere prepared by a number of house officers with no particular interest in the delineation of dementia, and that the rating of the records was done retrospectively by the author. Those cases showing only a falling off of memory, or only mild, unwonted emotional lability, or only an intellectual impairment that was so indefinite that the help of a psychologist was sought, were rated as "slight". Those cases showing an almost complete dissolution of the personality, or such disorientation that constant nursing care was required, were rated as "marked". The cases falling between these extremes were rated as " moderately" demented. Such a rating may be thought invalid. Certainly demented people show a variety of early symptoms 
and may show a greater loss in some respects than others. Nevertheless, there is usually an overall impairment of mental function which gradually increases, and so a three-point scale may have some justification.

Likewise cerebral atrophy may declare itself in the A.E.G. in a variety of ways; there may be generalized or localized enlargement of sulci, dilatation of the ventricular system in part or in whole, or any combination of these. Furthermore, if one abnormality is demonstrated, a search for other defects is often not made ; thus if the lateral ventricles are clearly dilated a special effort to delineate the cortical sulci may not be made, or if enlarged sulci are demonstrated in one part of the cortex a careful survey of other parts of the cortex will not usually be carried out. As there is little tendency towards global atrophy apparent in the A.E.G.s, to rate the degree of atrophy is impossible ; in the Tables, therefore, it is stated as either present or absent. Strictly speaking the radiologist concerned reported that atrophy was or was not demonstrated, and in the latter category fell a number of cases in which the examination did not fully satisfy him. An attempt to correlate various features of the A.E.G. with the presence or absence of dementia is made later.

Table I shows that of the 68 cases of dementia $85 \%$ showed cerebral atrophy in the A.E.G. and $15 \%$ did not. The question was raised whether the proportion of cases showing cerebral atrophy would be changed if stricter criteria were used in selecting the cases. Perhaps, for example, most of the cases showing dementia without radiological atrophy were arteriopathic. These 68 cases were therefore reviewed again and all cases were rejected which, according to Rothschild (1941), were likely to have predominant cerebral arteriosclerosis, i.e., with any of the following: prominent anxiety, fluctuating course, conspicuous preservation of insight, attacks of giddiness, a diastolic blood pressure greater than $120 \mathrm{~mm} . \mathrm{Hg}$, or associated Parkinsonism or coronary artery disease. Eighteen cases were rejected in this way, but of the remainder the proportion that showed cerebral atrophy was unaltered, namely $84 \%$ (Table II). This suggests either that the association of dementia with cerebral atrophy is independent of whether the cause is arteriosclerosis or some other process, or that Rothschild's criteria are unsound.

In the original 68 cases there were 10 that showed dementia but no atrophy and a closer inspection of them may be worth while. In the first place, slight dementia was significantly more frequent amongst these 10 cases than amongst the 58 cases that showed
TABLE II

INCIDENCE OF CEREBRAL ATROPHY IN CASES OF DEMENTIA AFTER EXCLUDING MOST ARTERIOPATHIES

\begin{tabular}{c|c|c|c}
\hline Age & $\begin{array}{c}\text { No. of Cases } \\
\text { of Dementia } \\
\text { Examined by } \\
\text { A.E.G. after } \\
\text { Excluding Most } \\
\text { Arteriopathies }\end{array}$ & $\begin{array}{c}\text { No. of Cases } \\
\text { of Dementia } \\
\text { with Atrophy }\end{array}$ & $\begin{array}{c}\text { No. of Cases } \\
\text { of Dementia } \\
\text { without Atrophy }\end{array}$ \\
\hline $45-$ & 5 & 4 & 1 \\
$50-$ & 12 & 11 & 1 \\
$55-$ & 18 & 16 & 4 \\
$60-$ & 4 & 4 & 0 \\
\hline 65 & 50 & $42(84 \%)$ & $8(16 \%)$ \\
\hline Total & -11 & 4 & 8 \\
\hline
\end{tabular}

atrophy. Thus, out of 27 cases with a slight degree of dementia only $19(70 \%)$ showed cerebral atrophy, whereas from among 41 cases with moderate or marked dementia $39(95 \%)$ showed atrophy; this difference is highly significant $\left(\chi^{2}=10.05 ; \mathbf{P}<0.01\right)$. Follow-up by letter at least one year after discharge from hospital showed that, as discussed later, there are reasons to doubt the accuracy of the diagnosis of dementia in these 10 cases in that out of six successfully traced only one had deteriorated. In the second place, a new scrutiny of the films revealed that of the 10 cases there was only one indubitably normal A.E.G.; in three the examination, though normal so far as it went, was inadequate to exclude some degree of atrophy; and in six there were borderline abnormalities (Table III). Thus only one case was known for certain to have demented progressively despite an almost normal A.E.G.

TABLE III

FOLLOW-UP OF 10 CASES ORIGINALLY REPORTED AS DEMENTED WITHOUT EVIDENCE OF CEREBRAL ATROPHY

\begin{tabular}{|c|c|c|}
\hline Rescrutinized A.E.G. & $\begin{array}{l}\text { Length of } \\
\text { Follow-up } \\
\text { (years) }\end{array}$ & $\begin{array}{l}\text { Mental State } \\
\text { at Follow-up }\end{array}$ \\
\hline $\begin{array}{c}\text { Normal } \\
, " \text { but incomplete }\end{array}$ & $\begin{array}{l}3 \\
4 \\
1\end{array}$ & $\begin{array}{l}\text { Well } \\
\text { Well } \\
\text { Well }\end{array}$ \\
\hline Sulc̈i enlarged to $\ddot{5} \mathrm{~mm}$. & $1 / 12$ & Died demented \\
\hline 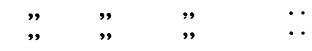 & $\overline{-}$ & 二 \\
\hline Ventricles" slightly" enlarged.. & $\overline{2}$ & $\begin{array}{l}\text { Died but not } \\
\text { demented }\end{array}$ \\
\hline $\begin{array}{c}\text { Sulci enlarged } \\
5 \mathrm{~mm} .\end{array}$ & 1 & \\
\hline
\end{tabular}

We must next consider how often cerebral atrophy is found when there is no evidence of dementia. During the same period and in the same age group a number of cases of cerebral atrophy came to light through A.E.G.s performed in the investigation of conditions other than dementia, usually cases suspected of having a cerebral tumour. There were 41 such cases, but this number was reduced to 24 
if those cases were excluded in which a definite diagnosis could be made to account for the atrophy, viz., disseminated sclerosis, thrombosis of the common carotid artery, cerebrovascular accident, neurosyphilis, infiltrating glioma, and infantile hemiplegia. The majority of the 24 were finally labelled " epilepsy of late onset", fits being significantly more common in these cases than in those with dementia in addition to the atrophy $\left(\chi^{2}=\right.$ $18.46 ; \mathrm{P}<0.001$-see Table IV). But in the absence of a follow-up study the exact contents of this group remain indefinite.

TABLE IV

INCIDENCE OF FITS IN CASES OF CEREBRAL ATROPHY WITH AND WITHOUT DEMENTIA

\begin{tabular}{l|c|ccc}
\hline \multirow{2}{*}{ Age } & $\begin{array}{c}\text { No. of Cases of Atrophy } \\
\text { with Dementia }\end{array}$ & $\begin{array}{c}\text { No. of Cases of Atrophy } \\
\text { without Dementia }\end{array}$ \\
\hline & Fits & No Fits & Fits & No Fits \\
\hline $45-$ & 3 & 3 & 6 & 1 \\
$50-$ & 4 & 12 & 4 & 0 \\
$55-$ & 5 & 14 & 5 & 1 \\
$60-$ & 3 & 9 & 4 & 1 \\
65 & 1 & 4 & 0 & 5 \\
\hline & 16 & 42 & 19 & \\
\hline
\end{tabular}

It might seem that the discovery of 24 cases of cerebral atrophy, when none was suspected from the mental state of the patient, diminishes the value of the A.E.G. But it should be remembered that these 24 cases came to light in a very large number of A.E.G.s performed for a variety of reasons, actually 213, of which 189 showed some lesion other than atrophy, or were normal (Table V). That is, of 213 A.E.G.s performed for various reasons in cases without any dementia only 24 , or $11 \%$, showed cerebral atrophy that could not be explained.

TABLE V

INCIDENCE OF CEREBRAL ATROPHY IN A.E.G.S PERFORMED FOR REASONS OTHER THAN DEMENTIA

\begin{tabular}{c|ccc}
\hline Age & $\begin{array}{c}\text { No. of Cases } \\
\text { without Dementia } \\
\text { but with Atrophy }\end{array}$ & $\begin{array}{c}\text { No. of Cases } \\
\text { without Dementia } \\
\text { or Atrophy }\end{array}$ & Total \\
\hline $45-$ & 7 & 69 & 67 \\
$50-$ & 6 & 55 & 61 \\
$55-$ & 5 & 32 & 37 \\
$60-$ & 5 & 29 & 34 \\
65 & 1 & 13 & 14 \\
\hline Total & $24(11 \%)$ & 189 & 213 \\
\hline
\end{tabular}

Criteria of Usefulness of the A.E.G.

The same data can also be used to determine what features of the A.E.G. are most useful in predicting the presence of dementia, and how well they do it.

Scrutiny of the A.E.G. films was kindly undertaken by Dr. G. Thomson, who knew that cerebral atrophy was the subject under investigation but who knew nothing of the individual cases. Films of the following cases were assembled in random order : 54 cases of dementia with atrophy (the films of the other four could not be traced), 10 cases of dementia without atrophy and 24 cases of atrophy without dementia, making 88 in all (Tables I and V). Each set of films consisted of the six standard positions (Lysholm, 1935) and was examined for the following six features (Fig. 1), and the results noted down on the back of the clinical abstract :

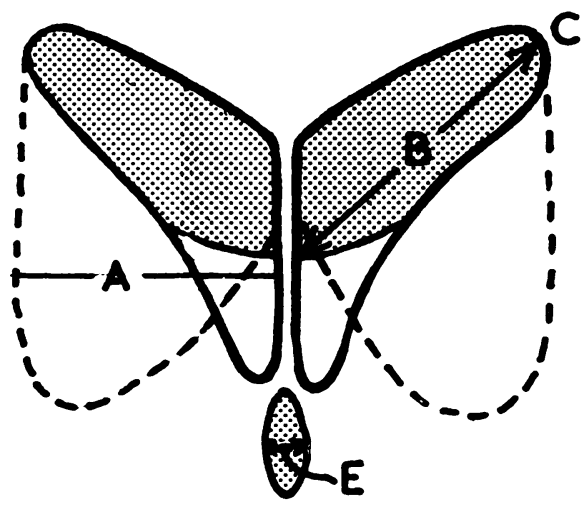

FIG. 1

$\mathrm{A}=$ Width of anterior horn of lateral ventricle.

B = Diagonal diameter of body of lateral ventricle.

$\mathrm{C}=$ Upper angle of lateral ventricle.

$\mathrm{D}=$ General configuration of lateral ventricle.

$E=$ Transverse diameter of third ventricle.

$\mathrm{F}=$ Width of cortical sulci.

The upper limits of normal for A and B were taken arbitrarily as $2.6 \mathrm{~cm}$. and for $\mathrm{E}$ as $0.8 \mathrm{~cm}$. Evans (1942) found in 53 normal adults and children no case in which the transverse diameter of both anterior horns together was greater than $4.4 \mathrm{~cm}$. Our upper limit for A would give a corresponding figure of $5.2 \mathrm{~cm}$., and so we are not likely to have inflated our abnormal group with borderline normals. Davies and Falconer (1943) measured the diagonal width of the body of the lateral ventricles in 50 cases thought to be normal and found none greater than $2 \cdot 2 \mathrm{~cm}$. Thus our upper limit for $\mathbf{B}$ is also conservative. Davidoff and Dyke (1951) found the transverse diameter of the third ventricle not to exceed $0.8 \mathrm{~cm}$. in 150 normal subjects. The upper angle $C$ was judged by the eye as normal or widened. Cortical sulci were measured whenever possible and were rated as normal (up to $0.2 \mathrm{~cm}$.), slightly enlarged $(0.2$ to $0.5 \mathrm{~cm}$.), and greatly enlarged (over $0.5 \mathrm{~cm}$.). Davidoff and Dyke (1951) found normal sulci rarely greater than $0.3 \mathrm{~cm}$. These norms, however, leave out of account the factor of age. 
Heinrich (1939), in examining the A.E.G.s of 100 normal individuals, found a progressive enlargement of the ventricles and subarachnoid space with age which was particularly marked over the age of 60 but he gives no figures. Furthermore, all these features could not be inspected in every case because of inadequate filling with air, the commonest omission being thorough visualization of the sulci.

The cases were sorted into three groups: one, those showing no dementia, numbering 24 ; two, those showing moderate or marked dementia, numbering 39 ; the remainder, consisting of 25 cases of slight dementia, were ignored, as they included a number in which the dementia was indefinite or so slowly progressive that it seemed to fall outside the usual clinical categories. The first two groups were then inspected for features of the A.E.G. that distinguished them most clearly. Only 16 of the first group and 28 of the second allowed adequate examination of both cortex and ventricles. The two groups were best distinguished by the presence of any of the following : (1) Cortical sulci greater than $0.5 \mathrm{~cm}$., (2) air trapped in the insular region of the cortex, (3) enlargement of one or both of the lateral ventricles particularly marked in the region of the trigone, whether or not they were enlarged elsewhere.

Using these criteria 12 out of 16 cases without dementia were correctly classified and 23 out of 28 cases with dementia (Table VI). No other features were useful in distinguishing the two groups. The validity of these criteria must be tested on another collection of demented and non-demented cases.

TABLE VI

DERIVATION AND VALIDATION OF A.E.G. CRITERIA

\begin{tabular}{|c|c|c|c|c|c|}
\hline $\begin{array}{c}\text { Experi- } \\
\text { ment }\end{array}$ & Group & $\begin{array}{l}\text { No. of } \\
\text { Cases }\end{array}$ & $\left|\begin{array}{c}\text { Correctly } \\
\text { Sorted by } \\
\text { Criteria }\end{array}\right|$ & $\begin{array}{l}\text { Wrongiy } \\
\text { Sorted by } \\
\text { Criteria }\end{array}$ & $\begin{array}{c}\text { Mis- } \\
\text { classified } \\
(\%)\end{array}$ \\
\hline \multirow{2}{*}{$\begin{array}{c}\text { Deriva- } \\
\text { tion }\end{array}$} & \multirow{2}{*}{$\begin{array}{l}\text { Cases without } \\
\text { dementia } \\
\text { Cases with } \\
\text { dementia }\end{array}$} & 16 & 12 & 4 & 25 \\
\hline & & 28 & 23 & 5 & 18 \\
\hline \multirow{2}{*}{$\begin{array}{c}\text { Valida- } \\
\text { tion }\end{array}$} & \multirow{2}{*}{$\begin{array}{l}\text { Cases without } \\
\text { dementia } \\
\text { Cases with } \\
\text { dementia }\end{array}$} & 12 & 9 & 3 & 25 \\
\hline & & 5 & 4 & 1 & 20 \\
\hline
\end{tabular}

Such a collection, though small in number, is provided by the 25 cases of slight dementia that were ignored. As has been seen, some of the patients rated as slightly demented were found on follow-up to show no deterioration of their mental state. In the age groups under review most dementias are progressive, and so, while not conclusive evidence, a report that the patient was improved or had not deteriorated in his mental capacity at least a year after leaving hospital may be considered to indicate that the original classification as " slightly demented" was mistaken. In this collection, therefore, follow-up provides us with a group of cases of undoubted dementia, and a group in which dementia is very unlikely. Our A.E.G. criteria may then be validated against these two groups.

Of the 25 cases only 22 had adequate A.E.G.s available. These 22 cases were followed up by mail at least a year after they had left hospital, and 17 replies were received; from them it appeared that five were demented and 12 were in fact not demented. These 17 cases were arranged according to the A.E.G. criteria and the correctness of the prediction of dementia determined (Table VI). As will be seen, the prediction was correct in about three cases out of four. Validation of these criteria is desirable on a much larger series of cases.

\section{Discussion}

This paper contributes little to fundamental knowledge of cerebral atrophy and dementia; rather is it a retrospective survey of the results of routine investigation. Attempts have been made in the past to correlate ventricular size at necropsy with the pathological changes in the cortex characteristic of senile and presenile dementia (Morel and Wildi, 1953), but I am not aware of any study consisting of more than a few isolated examples in which evidence in the A.E.G. of cerebral atrophy is related to the presence or absence of dementia. The results here presented have doubtless been suspected by most clinicians for some time, and in so far as they indicate clearly the usefulness of the A.E.G. in cases presenting with dementia they may modify routine practice. A different selection of cases may then be investigated and it is unlikely that what has been found to hold true in the present group will be found to apply exactly to a new selection. If, for example, many cases of very slight dementia are included, the figures presented here may be found to have little relevance. For this reason some of the more important factors determining the nature of this material are worth discussing.

The cases of organic dementia coming to the National Hospital are by no means representative of the condition. For example, cases showing the typical picture in which further investigation is not thought justifiable will be less often referred; or again, cases with excitement as a prominent early symptom are likely to be sent to a mental observation ward and thence to a mental hospital and so never to appear in our series. Even after admission to the wards, by no means every case of dementia is 
investigated with an A.E.G. Different physicians vary in their zeal for special diagnostic techniques and change their habits as experience teaches them. One operable tumour masquerading as Alzheimer's disease but diagnosed too late will lead to a flurry of radiological investigation and biopsies. Our material has been amassed by more than a dozen different physicians over a period of four years, and so the selection of an exactly comparable group is not to be expected.

The recognition of dementia depended more on current clinical practice than on explicit criteria, and inspection of the records often raised doubts as to whether correct deductions were drawn from the patient's behaviour. It is notoriously difficult to assess quickly the intellectual capacity in some cases of Parkinsonism, depression with hypochondriasis or dysphasia, for example, and often no searching attempt was made as its clinical significance might at the time seem to be small.

The assessment of cerebral atrophy in the A.E.G. has been described briefly, but the limits of normality are not certain and minor discrepancies were found between the readings of several radiologists. Observer error is notorious in all medicine and the radiologists have gone some way towards estimating it (Birkelo, Chamberlain, Phelps, Schools, Zacks, and Yerushalmy, 1947). But in this study no measures were made of inter-individual or intraindividual reliabilities, and the results once more reflect routine practice of a high standard rather than a precise research technique.

Lastly, the clinical diagnosis was rarely confirmed by post-mortem studies or even by long-term follow-up. But by restricting the material to patients over the age of 45 and by excluding various recognizable diseases, a fairly common and clear-cut clinical problem was investigated even though a number of different disease processes were included.

\section{Summary}

In routine clinical practice at least $85 \%$ of 68 cases of unexplained dementia in later life showed evidence of cerebral atrophy in the A.E.G.

In 213 A.E.G.s performed in the investigation of cases without dementia $11 \%$ showed an unexplained cerebral atrophy, and these were most commonly associated with epilepsy of late onset.

Features of the A.E.G. that suggest an associated dementia are cortical sulci greater than $0.5 \mathrm{~cm}$., air trapped in the insular region, and enlargement of the lateral ventricles particularly marked in the region of the trigone.

The author was seconded from the Maudsley Hospital, London, while this work was being done, and he wishes to thank Dr. J. St. C. Elkington for suggesting the investigation and for many helpful criticisms, and the Medical Committee of the National Hospital, London, for allowing him to use the clinical records of patients under the care of various physicians. He owes a special debt of gratitude to Dr. Gordon Thomson, who did all the radiological work, and wishes to thank Dr. E. A. Carmichael, Dr. Hugh Davies, and Dr. Vera Norris for reading the manuscript.

\section{REFERENCES}

Birkelo, C. C., Chamberlain, W. E., Phelps, P. S., Schools, P. E., Zack, D., and Yerushalmy, J. (1947). J. Amer. med. Ass., $133,359$.

Chodoff, P., Simon, A., and Freeman, W. (1948). Amer. J. Roentgenol., 59, 311 .

Davidoff, L. M., and Dyke, C. G. (1951). The Normal Encephalogram, 3rd ed. Kimpton, London.

Davies, H., and Falconer, M. A. (1943). Journal of Ncurology, Neurosurgery and Psychiatry, 6, 52.

Evans, W. A., Jr. (1942). Arch. Neurol. Psychiat., Chicago, 47, 931. Heinrich, A. (1939). Z. Altersforsch., 1, 345.

Lysho!m, E. (1935). Acta Radiol., Siockh., Suppl. XXIV.

McMenemey, W. H. (1941). Journal of Neurology, Neurosurgery and Psychiatry, $4,48$.

Morel, F., and Wildi, E. (1953). Schweiz. Arch. Neurol. Psychiat.,

Rothschild, D., (1941). Amer. J. Psychiat., 98, 324. 